\title{
Alternative spatial reference systems: Intentional vs. incidental learning
}

\author{
HOWARD S. HOCK and MARY SULLIVAN \\ Florida Atlantic University, Boca Raton, Florida 33431
}

\begin{abstract}
Subjects were initially shown unfamiliar polygons while their heads were tilted and were then tested for their ability to recognize the polygons when their heads were upright. The objective (gravitational) orientation of the polygons during acquisition affected recognition accuracy only when the polygons were acquired under intentional learning instructions. When acquisition was incidental, evidence for the retention of retinally referenced memory representations was obtained. These results were consistent with a review of previous literature indicating that the use of a task requiring either the storage or retrieval of information from memory is a necessary (although not sufficient) condition for obtaining an effect of objective orientation on performance.
\end{abstract}

A variety of perceptual phenomena depend on the orientation of the visual stimulus. Vertical and horizontal line gratings produce greater evoked brain potentials (Maffei \& Campbell, 1970) and longer afterimages (Wade, 1972) than do tilted (45-deg oblique) line gratings. Similarly, familiar stimuli are easier to recognize when they are presented in their upright, normal orientation than when they are rotated into an unfamiliar orientation (Dearborn, 1899; Gibson \& Robinson, 1935; Rock, 1973). Orientation effects of this kind indicate that a spatial reference system is involved in visual perception. However, unless special experimental procedures are introduced, the potential effects of objective (gravitational) and retinal reference systems are confounded. That is, when a subject whose head is in an upright posture observes a tilted stimulus, the stimulus is tilted with respect to both gravity and the retina. The traditional procedure for distinguishing between these alternatives has been to alter the observer's posture so that his/her head can be aligned with the tilted stimulus. This procedure allows for the direct contrast of performance between conditions in which: (1) the stimulus is objectively upright but retinally tilted, and (2) the stimulus is retinally upright but objectively tilted. When performance is better in Condition 1 than Condition 2, it indicates that orientation effects depend on an objective (gravitational) spatial reference system.

This paper is based on the thesis submitted by M. Sullivan, in partial fulfillment of requirements for the master's degree, to the Department of Psychology, Florida Atlantic University. The authors would like to thank Elizabeth Webb for her help in conducting the experiments and David Bjorklund for his careful reading of the manuscript. Requests for reprints should be sent to Howard S. Hock, Department of Psychology, Florida Atlantic University, Boca Raton, Florida 33431. M. Sullivan is currently at the University of Texas.
When performance is better in Condition 2 than in Condition 1, it indicates that orientation effects depend on a retinal spatial reference system.

The results of many experiments provide evidence for the use of a retinal spatial reference system. As indicated above, Maffei and Campbell (1970) have shown, for upright subjects, that vertical and horizontal line gratings produce greater evoked brain potentials than do oblique line gratings. Frost and Kaminer (1975) found that when subjects' heads are tilted $45 \mathrm{deg}$, the gratings that are retinally vertical or horizontal (but objectively oblique) produce greater evoked potentials than the gratings that are objectively vertical or horizontal (but retinally oblique). Also described above is Wade's (1972) finding, for upright subjects, that vertical and horizontal line gratings produce longer afterimages than do oblique line gratings. In a subsequent experiment, Wade (1973) showed that when subjects' heads are tilted $45 \mathrm{deg}$, the afterimage lasts longer when the grating is retinally vertical or horizontal (but objectively oblique) than when it is objectively vertical or horizontal (but retinally oblique). In still another experiment involving line gratings, Campbell, Kulikowski, and Levinson (1970) showed, for upright subjects, that acuity (being able to detect closely spaced dark lines on a light background) was greater for vertical and horizontal than for oblique gratings. Banks and Stolarz (1975) introduced a head tilt manipulation into this task and found that acuity depended on the retinal rather than the objective orientation of the gratings.

Olson and Attneave (1970) studied perceptual grouping in a task requiring subjects to identify the discrepant quadrant in circular arrays of line segments. Subjects performed more rapidly when the arrays were composed of vertical and horizontal line segments (e.g., vertical segments in one quadrant, 
horizontal segments in the other three quadrants) than when the arrays were composed of +45-deg and -45-deg oblique line segments. When subjects' heads were tilted $45 \mathrm{deg}$, response times were faster when the line segments were retinally vertical and horizontal (but objectively oblique) than when they were objectively vertical and horizontal (but retinally oblique). Gillam and McGrath (1979) created stimuli equivalent to the two-dimensional projection of pairs of lines rotating in three-dimensional space. Spontaneous reversals in the perceived direction of rotation were sometimes coincident for the two lines and sometimes resulted in their rotating in opposite directions. Coincident rotation, a measure of perceptual unity for Gillam and McGrath, was greater when the rotation was around a horizontal axis than when it was around a vertical axis. When subjects' heads were tilted $90 \mathrm{deg}$, coincident rotation occurred more frequently around the retinally horizontal (but objectively vertical) axis than the objectively horizontal (but retinally vertical) axis. Finally, Corballis and Roldan (1975) measured the time required for subjects to judge whether or not a pair of patterns was symmetrical with regard to an intermediate axis. They found that reaction times were faster when the stimulus axis was upright than when it was tilted. When subjects' heads were tilted $45 \mathrm{deg}$, reaction times were faster when the stimulus axis was retinally upright (but objectively tilted) than when it was objectively upright (but retinally tilted).

In addition to providing evidence for the use of a retinal frame of reference, the experiments described above had one more thing in common. None of them required either remembering anything about the stimuli that were presented or retrieving information concerning the stimuli from long-term memory. In the experiments described below, the subjects' task involves either the storage or retrieval of stimulus information. Under these conditions, evidence that subjects use an objective (gravitational) frame of reference is obtained.

Attneave and Olson (1967) had subjects learn names (Adam, Albert, etc.) for four line segments differing in orientation $(0,+45,-45$, and $90 \mathrm{deg})$. They found, for subjects viewing the stimuli in an upright posture, that the vertical and horizontal lines were named more rapidly than the oblique lines. This difference turned out to depend on the objective (gravitational) orientation of the lines. For subjects viewing the stimuli with their heads tilted $45 \mathrm{deg}$, the objectively vertical and horizontal (but retinally oblique) lines were named faster than the objectively oblique lines, despite the latter's being retinally vertical and horizontal. In the second phase of Attneave and Olson's study, subjects who learned the names of the lines while upright were tilted $45 \mathrm{deg}$, and vice versa. They were told to use either the same names for lines that were physically or objectively the same or to use the same names for lines that were in the same relation to their heads (i.e., "just as if you rotated your head while reading and rotated the book at the same time'). The requirement to reassign names to the lines according to their retinal orientation instead of their objective orientation resulted in slower naming times for the latter instruction (i.e., to use a retinal reference system) than for the former instruction (i.e., to use an objective reference system).

Although Attneave and Olson's study provided evidence for the use of an objective spatial reference system, subsequent research indicated that memory representations for line segments could also be retinally referenced. Attneave and Reid (1968) instructed subjects, who learned the names of the line segments while they were in a tilted posture, to think of the tops of their heads as up and their chins as down and to relate the slants of the line segments to the axes of their heads. Using this instruction, they found that retinally vertical and horizontal (but objectively oblique) lines were named faster than retinally oblique lines, despite the latter's being objectively vertical and horizontal. Thus, subjects given no specific instructions "prefer" an objective spatial reference system (Attneave \& Olson, 1967), but subjects can, if required, use a retinal spatial reference system in coding memory representations of visual stimuli (Attneave \& Reid, 1968).

In an experiment based on a paradigm first used by Cooper and Shepard (1973), Corballis, Zbrodoff, and Roldan (1976) had subjects determine whether alphabet letters in various orientations were normal or mirror-image reversed. Subjects' response times in this task indicate that they must mentally rotate stimuli to upright in order to make this discrimination. When Corballis et al. introduced the manipulation of head tilt into this paradigm, they found that subjects mentally rotated the letters into their objectively upright orientation, even if the letters were retinally upright when they were presented. In a subsequent study, Corballis, Nagourney, Shetzer, and Stefanatos (1978) found that this bias to mentally rotate to objective (gravitational) upright was maintained under conditions in which tilted visual frames produced some influence of a retinal frame of reference.

The identification of familiar figures also seems to depend primarily on their objective orientation. Rock (1956) had subjects view ambiguous outline drawings with their heads tilted. Each drawing was positioned such that it looked like one thing (e.g., a dog) when it was perceived in relation to objective axes and like something else (e.g., a chef) when it was perceived in relation to retinal axes. Subjects consistently selected the objectively upright alternative. Other experiments, however, have shown that retinal 
orientation can also affect identification. Rock and Heimer (1957) have obtained substantial effects of both objective and retinal orientation in the identification of complex, fragmented drawings, and Steinfeld (1970) has provided evidence of significant effects of retinal orientation on the identification of briefly presented words. More recently, Corballis, Anuza, and Blake (1978) have shown that retinal orientation can predominate over objective orientation in a task involving the identification of alphabet letters that are briefly presented in the periphery of subjects' eyes.

Rock and Heimer (1957) have provided evidence that novel figures are coded in terms of their objective orientation at the time of acquisition. That is, subjects recognized previously seen figures (i.e., discriminated them from perceptually similar "distractor" figures) more accurately they were tested in the same objective orientation as during acquisition than when they were tested in the same retinal orientation as during acquisition. Once again, however, there was some indication of a retinal effect on recognition accuracy; retinal orientation (upright vs. tilted) affected the accuracy with which objectively tilted figures were recognized. This evidence-that novel figures are recognized more accurately when they are presented in the same objective orientation during acquisition and testing than when they are presented in the same retinal orientation during acquisition and testing - was also obtained by Rock (1956). He also found, however, that subjects switched to a retinal reference system when the visual frame surrounding the stimulus maintained the same orientation relative to the retina during acquisition and recognition testing.

Rock (1973) has contended that objectively referenced memory representations are formed by mentally rotating retinally referenced perceptual representations into objective upright. Corballis et al. (1976) have argued, however, that if a retinally referenced representation is always formed prior to an objectively referenced representation, tasks measuring reaction time should always produce faster responses when the stimulus is retinally upright than when it is objectively upright (unless mental rotation to objective upright were obligatory, which Attneave and Reid have shown is not the case). Evidence for faster responding in the objectively upright orientation (Attneave \& Olson, 1967; Corballis, Nagourney, et al., 1978; Corballis et al., 1976) thus provides evidence against Rock's dual representation hypothesis and in favor of the hypothesis that tilted subjects can set their spatial frame of reference to objective (gravitational) upright prior to the presentation of a stimulus. Referencing visual information to objective upright does not appear to be obligatory (Attneave \& Reid, 1968), but certain conditions seem to increase the likelihood that it will occur: (1) there is a task requirement to either store information in memory or retrieve information from long-term memory, (2) the perceptual demands of the task are not "excessive," and (3) neither the instructions given the subjects nor the visual frames surrounding the stimuli bias subjects to use a retinal reference system. In tasks for which there is no memory requirement, subjects appear to be quite consistent in using retinal axes. This retinal bias exists without introducing instructional biases or retinally upright visual frames around the stimulus. The results of experiments without a memory requirement suggests that operations involved in the formation of a perceptual representation (e.g., element detection, grouping, symmetry detection) are most readily performed with respect to a retinal frame of reference. It is for this reason, perhaps, that subjects in tasks that have a memory requirement set their spatial reference axes to objective upright only when the perceptual demands of the task are not "excessive." Thus, retinal factors have been shown to influence performance under conditions of perceptual difficulty: when stimuli are complex (e.g., fragmented drawings, words) and when they are presented for a brief period of time in uncertain peripheral locations (e.g., the alphabet letters in Corballis, Anuza, \& Blake, 1978).

The above conclusions rest on the comparison of many different experiments involving different kinds of stimulus materials and different kinds of experimental tasks. The purpose of the research reported in this paper was to provide empirical evidence to support these conclusions but with experiments having common stimuli and tasks. More specifically, the research tested the hypothesis that subjects would code visual stimuli in terms of their objective orientation only under conditions in which there was a memory requirement. The experiments involved the presentation of novel polygons under intentional and incidental learning conditions. This was followed by a yes-no recognition test. It was hypothesized that evidence of objectively referenced memory representation would be obtained only for subjects in the intentional learning condition.

\section{METHOD}

The experiments were conducted in two phases. Phase 1 , acquisition, involved incidental learning in Experiment 1 and intentional learning in Experiment 2. Phase 2 comprised a yes-no recognition test in both experiments.

\section{Stimuli}

The stimuli consisted of 32 random polygons selected from the set generated by Attneave and Arnoult (1956). Two sets of 16 (designated $A$ and $B$ ) were assembled, each set comprising eight six-sided polygons and eight eight-sided polygons. The polygons in Sets A and B were matched, on a pair-wise basis, with regard to number of sides, overall size, global shape, and the presence of 
such salient characteristics as an arrow-like feature or the reversal of direction of adjacent sides to form a "jaw." Although these matched pairs were never presented simultaneously, their orientations were coordinated in the Phase 2 recognition test, and responses to both were combined in a signal detection analysis of the recognition data. For example, if responses to Polygon Al were included in the computation of the hit rate for a particular condition in the recognition test, responses to Polygon Bl would be included in the computation of the false alarm rate for that condition.

The upright $(0-\mathrm{deg})$ orientation at which the 16 polygons were seen during acquisition was arbitrarily defined for each polygon. The upright orientation for each polygon was selected such that none of the sides of the polygon were vertical or horizontal. This was done to ensure that the polygons would not be more recognizable in their objectively upright orientation due to the alignment of their sides with objective vertical or horizontal axes.

\section{Design}

During acquisition (Phase 1), subjects were presented the polygons from Set A or Set B in the arbitrarily defined 0-deg (objectively upright) orientation of the polygons. The polygons were viewed while the subjects' heads were inclined so that their retinas were tilted either $45 \mathrm{deg}$ to the left or $45 \mathrm{deg}$ to the right of upright. During recognition testing (Phase 2), subjects' heads were always upright. They were presented a random sequence of polygons from Sets A and B and were required to indicate whether or not they had seen each previously. For half the subjects, Set A comprised the "originals" in the recognition test (they were presented previously during Phase 1), and Set B comprised the "distractors." The reverse was true for the other half of the subjects.

Every subject was tilted both left and right in Phase 1 in order to control for individual biases in direction of mental rotation during the Phase 2 recognition test. The necessary counterbalancing generated the eight acquisition conditions indicated in Table 1. Half the subjects viewed the first eight polygons (four six-sided, four eight-sided) with their heads tilted left and the second eight polygons (four six-sided, four eight-sided) with their heads tilted right. The other half viewed the first eight with heads tilted right and the second eight with heads tilted left. Within each subset of eight polygons, the order of presentation was randomized for each subject.

In the Phase 2 recognition test, subjects with their heads upright, were presented a random sequence of the 32 polygons from Sets $\mathbf{A}$ and $\mathbf{B}$. The polygons were presented in one of four different orientations. These orientations were keyed to the direction of tilt of subjects' heads in Phase 1 (see Figure 1). For polygons that were viewed while subjects' heads were tilted left during

Table 1

Design of the Acquisition Phase

\begin{tabular}{cccccc}
\hline & \multicolumn{2}{c}{$\begin{array}{c}\text { First } \\
\text { Pight }\end{array}$} & & \multicolumn{2}{c}{$\begin{array}{c}\text { Second Eight } \\
\text { Presentations }\end{array}$} \\
\cline { 2 - 3 } $\begin{array}{c}\text { Acquisi- } \\
\text { tion Con- } \\
\text { dition }\end{array}$ & $\begin{array}{c}\text { Head } \\
\text { Tilt }\end{array}$ & $\begin{array}{c}\text { Assigned } \\
\text { Stimuli }\end{array}$ & & $\begin{array}{c}\text { Head } \\
\text { Tilt }\end{array}$ & $\begin{array}{c}\text { Assigned } \\
\text { Stimuli }\end{array}$ \\
\hline 1 & Left & A1-A8 & & Right & A9-A16 \\
2 & Left & B1-B8 & & Right & B9-B16 \\
3 & Right & A9-A16 & & Left & A1-A8 \\
4 & Right & B9-B16 & & Left & B1-B8 \\
5 & Left & A9-A16 & & Right & A1-A8 \\
6 & Left & B9-B16 & & Right & B1-B8 \\
7 & Right & A1-A8 & & Left & A9-A16 \\
8 & Right & B1-B8 & & Left & B9-B16 \\
\hline
\end{tabular}

Note-When the Set $A$ stimuli were presented in the acquisition phase, the Set $B$ stimuli were presented as distractors in the test phase, and vice versa.

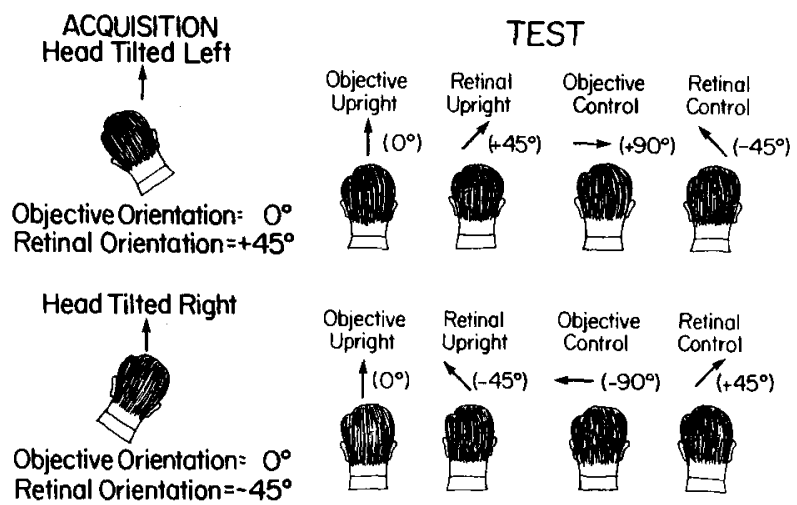

Figure 1. Illustration of the relationship between head and stimulus orientation during acquisition (Phase 1) and the recognition test (Phase 2).

Phase 1, the Phase 2 test orientations were as follows: (1) The test polygons in the objective-upright position remained at $0 \mathrm{deg}$. (2) The test polygons in the objective-control condition were presented 90 deg clockwise $(+90 \mathrm{deg})$ from their original Phase 1 orientation. If there were only retinally referenced memory representations for the polygons acquired during Phase 1 , there should have been no difference in recognition accuracy between the polygons tested in the objective-upright and objective-control conditions (both were $45 \mathrm{deg}$ from retinal upright). (3) The test poly. gons in the retinal-upright condition were presented in an orientation $45 \mathrm{deg}$ clockwise $(+45 \mathrm{deg})$ from their original Phase 1 orientation. This placed the polygons in the same orientation relative to the retina as in Phase 1 of the experiment. (4) The test polygons in the retinal-control condition were presented $45 \mathrm{deg}$ counterclockwise $(-45 \mathrm{deg})$ from their Phase 1 orientation. If there were only objectively referenced memory representations for the polygons acquired during Phase 1 , there should have been no difference in recognition accuracy between the polygons tested in the retinal-upright and retinal-control conditions (both were $45 \mathrm{deg}$ from objective upright).

The above description pertains to polygons viewed while the subjects were tilted to the left during Phase 1 . The parallel conditions were provided for polygons viewed while subjects were tilted to the right during Phase 1 . By using this design, we could assess both retinal and objective effects on recognition accuracy without having to introduce potentially confounding effects of subject discomfort and activation level (Horn, 1965; Jung, Kornhuber, \& DaFonseca, 1963) in comparing recognition performance between head-upright and head-tilted conditions. Subjects who, during Phase 1, saw Polygons 1-8 while their heads were tilted left and Polygons 9-16 while their heads were tilted right (Acquisition Condition 1, 2, 3, or 4) were assigned to one of the four test conditions ( $a, b, c$, or d) detailed in the top half of Table 2. Subjects who, during Phase 1, saw Polygons 1-8 while their heads were tilted right and Polygons 9-16 while their heads were tilted left (Acquisition Condition 5, 6, 7, or 8) were assigned to one of the four test conditions ( $c, d, e$, or $f$ ) detailed in the bottom half of Table 2. When counterbalanced over all eight test conditions, every polygon appeared equally often in each test orientation.

\section{Procedure}

During Phase 1, each subject's head was tilted so that it rested on a cushioned surface tilted $50 \mathrm{deg}$ (or $-50 \mathrm{deg}$ ) from upright. Five degrees were added to the desired angle (of +45 or $-45 \mathrm{deg}$ ) to compensate for counterrolling of the eyes (Miller, 1962). For each subject, the height of the chair was adjusted so that resting the head at that angle was as comfortable as possible. Although the stimuli were presented with the overhead room lights turned 
Table 2

Design of Recognition Phase (Coordinated to Acquisition Condition)

\begin{tabular}{|c|c|c|c|c|c|c|c|c|c|}
\hline & & \multicolumn{8}{|c|}{ Recognition Test Orientations } \\
\hline & & \multicolumn{4}{|c|}{$\begin{array}{l}\text { For Stimuli Seen While Subjects Are Tilted } \\
\text { Left During Acquisition }\end{array}$} & \multicolumn{4}{|c|}{$\begin{array}{c}\text { For Stimuli Seen While Subjects Are Tilted } \\
\text { Right During Acquisition }\end{array}$} \\
\hline \multicolumn{2}{|c|}{ Condition } & \multicolumn{2}{|c|}{ Objective } & \multicolumn{2}{|c|}{ Retinal } & \multicolumn{2}{|c|}{ Objective } & \multicolumn{2}{|c|}{ Retinal } \\
\hline $\begin{array}{l}\text { Acquisi- } \\
\text { tion }\end{array}$ & $\begin{array}{c}\text { Test- } \\
\text { ing }\end{array}$ & $\begin{array}{l}\text { Upright } \\
0 \text { deg }\end{array}$ & $\begin{array}{l}\text { Control } \\
+90 \text { deg } \\
\end{array}$ & $\begin{array}{l}\text { Upright } \\
+45 \text { deg } \\
\end{array}$ & $\begin{array}{l}\text { Control } \\
-45 \text { deg }\end{array}$ & $\begin{array}{l}\text { Upright } \\
0 \text { deg }\end{array}$ & $\begin{array}{l}\text { Control } \\
-90 \mathrm{deg} \\
\end{array}$ & $\begin{array}{l}\text { Upright } \\
-45 \mathrm{deg} \\
\end{array}$ & $\begin{array}{l}\text { Control } \\
+45 \mathrm{deg} \\
\end{array}$ \\
\hline $1,2,3$, or 4 & a & $\begin{array}{l}\text { A } 1,2 \\
\text { B } 1,2\end{array}$ & $\begin{array}{l}\text { A } 3,4 \\
\text { B 3,4 }\end{array}$ & $\begin{array}{l}\text { A5 } 6 \\
\text { B } 5,6\end{array}$ & $\begin{array}{l}\text { A7,8 } \\
\text { B 7,8 }\end{array}$ & $\begin{array}{l}\text { A9,10 } \\
\text { B } 9,10\end{array}$ & $\begin{array}{l}\text { A } 11,12 \\
\text { B } 11,12\end{array}$ & $\begin{array}{l}\text { A13,14 } \\
\text { B } 13,14\end{array}$ & $\begin{array}{l}\text { A } 15,16 \\
\text { B } 15,16\end{array}$ \\
\hline $1,2,3$, or 4 & $b$ & $\begin{array}{l}\text { A3,4 } \\
\text { B 3,4 }\end{array}$ & $\begin{array}{l}\mathrm{A} 1,2 \\
\mathrm{~B} 1,2\end{array}$ & $\begin{array}{l}\text { A7,8 } \\
\text { B 7,8 }\end{array}$ & $\begin{array}{l}\text { A5, } 6 \\
\text { B } 5,6\end{array}$ & $\begin{array}{l}\text { A11,12 } \\
\text { B } 11,12\end{array}$ & $\begin{array}{l}\text { A9,10 } \\
\text { B } 9,10\end{array}$ & $\begin{array}{l}\text { A } 15,16 \\
\text { B } 15,16\end{array}$ & $\begin{array}{l}\text { A13,14 } \\
\text { B } 13,14\end{array}$ \\
\hline $1,2,3$, or 4 & $\mathrm{c}$ & $\begin{array}{l}\text { A5,6 } \\
\text { B5 } 6\end{array}$ & $\begin{array}{l}\text { A 7,8 } \\
\text { B 7,8 }\end{array}$ & $\begin{array}{l}\mathrm{A} 1,2 \\
\mathrm{~B} 1,2\end{array}$ & $\begin{array}{l}\text { A3,4 } \\
\text { B 3,4 }\end{array}$ & $\begin{array}{l}\text { A13,14 } \\
\text { B } 13,14\end{array}$ & $\begin{array}{l}\text { A } 15,16 \\
\text { B } 15,16\end{array}$ & $\begin{array}{l}\text { A9,10 } \\
\text { B } 9,10\end{array}$ & $\begin{array}{l}\text { A } 11,12 \\
\text { B } 11,12\end{array}$ \\
\hline $1,2,3$, or 4 & d & $\begin{array}{l}\text { A7,8 } \\
\text { B 7,8 }\end{array}$ & $\begin{array}{l}\text { A5,6 } \\
\text { B 5,6 }\end{array}$ & $\begin{array}{l}\text { A3,4 } \\
\text { B 3,4 }\end{array}$ & $\begin{array}{l}\text { A1,2 } \\
\text { B 1,2 }\end{array}$ & $\begin{array}{l}\text { A15,16 } \\
\text { B } 15,16\end{array}$ & $\begin{array}{l}\text { A13,14 } \\
\text { B 13,14 }\end{array}$ & $\begin{array}{l}\text { A11,12 } \\
\text { B } 11,12\end{array}$ & $\begin{array}{l}\text { A } 9,10 \\
\text { B } 9,10\end{array}$ \\
\hline $5,6,7$, or 8 & $\mathrm{e}$ & $\begin{array}{l}\text { A9,10 } \\
\text { B } 9,10\end{array}$ & $\begin{array}{l}\text { A11,12 } \\
\text { B } 11,12\end{array}$ & $\begin{array}{l}\text { A13,14 } \\
\text { B 13,14 }\end{array}$ & $\begin{array}{l}\text { A15,16 } \\
\text { B } 15,16\end{array}$ & $\begin{array}{l}\text { A1,2 } \\
\text { B 1,2 }\end{array}$ & $\begin{array}{l}\text { A3,4 } \\
\text { B } 3,4\end{array}$ & $\begin{array}{l}\text { A5, } 6 \\
\text { B 5,6 }\end{array}$ & $\begin{array}{l}\text { A7,8 } \\
\text { B 7,8 }\end{array}$ \\
\hline $5,6,7$, or 8 & $\mathrm{f}$ & $\begin{array}{l}\text { A } 11,12 \\
\text { B } 11,12\end{array}$ & $\begin{array}{l}\text { A9,10 } \\
\text { B } 9,10\end{array}$ & $\begin{array}{l}\text { A15,16 } \\
\text { B } 15,16\end{array}$ & $\begin{array}{l}\text { A13,14 } \\
\text { B } 13,14\end{array}$ & $\begin{array}{l}\text { A3,4 } \\
\text { B 3,4 }\end{array}$ & $\begin{array}{l}\text { A } 1,2 \\
\text { B } 1,2\end{array}$ & $\begin{array}{l}\text { A7,8 } \\
\text { B 7,8 }\end{array}$ & $\begin{array}{l}\text { A5 } 6 \\
\text { B 5,6 }\end{array}$ \\
\hline $5,6,7$, or 8 & $\mathrm{~g}$ & $\begin{array}{l}\text { A13,14 } \\
\text { B } 13,14\end{array}$ & $\begin{array}{l}\text { A } 15,16 \\
\text { B } 15,16\end{array}$ & $\begin{array}{l}\text { A9,10 } \\
\text { B } 9,10\end{array}$ & $\begin{array}{l}\text { A } 11,12 \\
\text { B } 11,12\end{array}$ & $\begin{array}{l}\text { A5,6 } \\
\text { B 5,6 }\end{array}$ & $\begin{array}{l}\text { A7,8 } \\
\text { B 7,8 }\end{array}$ & $\begin{array}{l}\text { A1,2 } \\
\text { B } 1,2\end{array}$ & $\begin{array}{l}\text { A } 3,4 \\
\text { B } 3,4\end{array}$ \\
\hline $5,6,7$, or 8 & $\mathrm{~h}$ & $\begin{array}{l}\text { A } 15,16 \\
\text { B } 15,16 \\
\end{array}$ & $\begin{array}{l}\text { A13,14 } \\
\text { B } 13,14 \\
\end{array}$ & $\begin{array}{l}\text { A11,12 } \\
\text { B } 11,12 \\
\end{array}$ & $\begin{array}{l}\text { A9,10 } \\
\text { B } 9,10 \\
\end{array}$ & $\begin{array}{l}\text { A7,8 } \\
\text { B 7,8 }\end{array}$ & $\begin{array}{l}\text { A5,6 } \\
\text { B 5,6 }\end{array}$ & $\begin{array}{l}\text { A3,4 } \\
\text { B 3,4 } \\
\end{array}$ & $\begin{array}{l}\text { A 1,2 } \\
\text { B 1,2 }\end{array}$ \\
\hline
\end{tabular}

Note-The six-sided polygons are denoted by odd numbers and the eight-sided polygons by even numbers.

off, light "leakage" from the slide projector provided some illumination of the background. The background information comprised cues that were, for the most part, rectilinear (e.g., room corners, door frame, horizontal table top). The stimuli were individually rear-projected onto a circular translucent screen, small enough $(6.1 \mathrm{~cm}$ in diameter) that the vertical and horizontal edges of the slides were not visible to the subjects. Subjects' eyes were positioned $114 \mathrm{~cm}$ from the screen; the average visual angle subtended by the polygons was about $2.5 \mathrm{deg}$. Each slide was presented for approximately $5 \mathrm{sec}$ during Phase 1 . An interstimulus interval of approximately $5 \mathrm{sec}$ was introduced by inserting opaque cards in alternation with the stimulus slides in the Carousel projector.

During Phase 2, subjects sat in front of the screen with their heads upright. They were told that they were going to see the polygons they had just seen, but that these polygons would be mixed with polygons they had never seen before. They were to respond "yes" if they remembered seeing the polygon before and "no" if they did not recognize it. They were informed that some of the polygons they had seen before would be tilted when they saw them again and were asked to respond "yes" if they remembered seeing the polygon before, regardless of whether or not it was tilted. Subjects were told to keep their heads perfectly upright during this portion of the experiment and not to tilt their heads in any direction. The 32 test stimuli were presented one at a time, with the overhead lights off. The slide was changed only after a "yes" or "no" response was obtained.

Experiment 1: Incidental learning. Subjects in Phase 1 of this experiment were told that they would be shown polygons with unusual shapes. They were asked to give a rating for each polygon regarding how aesthetically pleasing or attractive it was to them. Their judgments were to be made with respect to a five-point scale, 5 denoting that a polygon was very pleasing and 1 denoting that it was very displeasing. Subjects were instructed to give their ratings verbally after the polygon was no longer on the screen. There was no instruction to remember any of the polygons. At the conclusion of the Phase 2 recognition test, the subjects were asked if they anticipated that there might be a memory test. Six subjects who responded affirmatively to this question were replaced by new subjects.

Experiment 2: Intentional learning. The acquisition and recognition testing procedure was identical in this experiment to that used in the incidental learning experiment, except for the acquisition instructions. Instead of the aesthetic judgment procedure used in Experiment 1, subjects in this experiment were told, at the start of Phase 1, to try to remember each polygon.

\section{Subjects}

One-hundred-and-twenty-eight unpaid volunteer subjects (64 per experiment) participated in this study. All but two were students at Florida Atlantic University. Half the subjects were male and half were female. The assignment of subjects to each of the acquisition and testing conditions was balanced according to sex.

\section{RESULTS}

For each subject, only eight polygons (four originals and four distractors) were presented for each of the four test orientations in the Phase 2 recognition test. In order to obtain greater stability in estimating proportions of hits and false alarms, pseudosubjects were formed by combining the data for groups of four subjects assigned to the same testing condition and matched acquisition conditions. For example, a pseudosubject was formed from the four subjects who were in Testing Condition a and had received Acquisition Condition 1 (Set A comprised originals) or Acquisition Condition 2 (Set B comprised orig- 
inals). ${ }^{1}$ Thus, the total of 128 subjects who participated in the study was collapsed into 16 pseudosubjects per experiment. The resulting mean rate of misses and false alarms and mean $d^{\prime}$ scores are presented in Tables 3 and 4.

\section{Experiment 1: Incidental Learning}

As can be seen in Table 3, the polygons in the retinal-upright condition were recognized with significantly better than chance accuracy $[t(15)=15.83$, $\mathrm{p}<.001]$. The mean error rate for this condition was $31.2 \%$; chance was $50 \%$. Of interest was whether successful recognition performance in this condition was due to the hypothesized retention of retinally referenced memory representations or whether it was due to mental rotation of the retinal-upright polygons into correspondence with objectively referenced memory representations. The "mental rotation" explanation could be ruled out since it required that there be no difference in recognition accuracy between the retinal-upright and retinal-control conditions. Both conditions involved polygon orientations that were 45 deg from objective upright, so that recognition based on mental rotation to objective upright was equally possible for both. As can be seen in Table 3, however, the retinal-upright polygons were recognized more accurately than the retinal-control polygons. This difference was significant $[t(15)=$ $2.87, p<.02$ ]. It could be concluded, therefore, that subjects retained retinally referenced memory representations for the incidentally learned polygons.

The polygons in the objective-upright condition were also recognized with significantly better than chance accuracy $[\mathrm{t}(15)=5.52, \mathrm{p}<.001]$; the mean error rate for this condition was $35.6 \%$. It could not be concluded, however, that subjects retained objectively referenced memory representations for the incidentally learned polygons. The difference in recognition accuracy between the objective-upright and objective-control orientations, both of which were $45 \mathrm{deg}$ from retinal-upright, was not significant $[\mathrm{t}(15)<1.0]$. Thus, we could not rule out the possibility that the objective-upright polygons (as well as the objective-control polygons) were recognized in this experiment by virtue of their being mentally ro-

Table 3

Experiment 1: Mean Percent Misses (M) and False Alarms (FA) and Mean d' Scores in the Recognition Test Following Incidental Learning

\begin{tabular}{lccccccc}
\hline & \multicolumn{3}{c}{ Objective } & & \multicolumn{3}{c}{ Retinal } \\
\cline { 2 - 5 } \cline { 6 - 8 } & $\mathrm{M}$ & FA & $\mathrm{d}^{\prime}$ & & $\mathrm{M}$ & FA & $\mathrm{d}^{\prime}$ \\
\hline $\mathrm{U}$ & 30.5 & 40.6 & .77 & 31.6 & 30.8 & 1.03 \\
$\mathrm{C}$ & 39.8 & 30.1 & .84 & 41.0 & 31.6 & .71 \\
$\mathrm{U}-\mathrm{C}$ & & & -.07 & & & .32 \\
\hline
\end{tabular}

Note-U = upright: $C=$ control. tated into correspondence with the retinally referenced memory representations. ${ }^{2}$

\section{Experiment 2: Intentional Learning}

As can be seen in Table 4, the polygons in the objective-upright condition were recognized with significantly better than chance accuracy $[\mathrm{t}(15)=9.46$, $\mathrm{p}<.001]$; the mean error rate for this condition was $29.9 \%$. Of interest was whether successful recognition performance in this condition was due to the hypothesized retention of objectively referenced memory representations or whether it was due to the mental rotation of the objective-upright polygons into correspondence with retinally referenced memory representations. The "mental rotation" alternative could be ruled out on the basis of the significantly more accurate recognition obtained in the objective-upright condition than in the objectivecontrol condition $[t(15)=2.74, p<.02]$. It could be concluded, therefore, that subjects retained objectively referenced memory representations for the intentionally learned polygons.

The polygons in the retinal-upright orientation were also recognized with better than chance accuracy $[t(15)=9.04, p<.001]$; the mean error rate for this condition was $30.3 \%$. There was, however, no indication that subjects retained retinally referenced memory representations for the intentionally learned polygons. Recognition accuracy was not significantly different for the retinal-upright than for the retinalcontrol condition $[\mathrm{t}(15)<1.0]$. Although this suggested that the retinal-upright polygons (as well as the retinal-control polygons) were recognized as a result of being mentally rotated into correspondence with the objectively referenced memory representations, the data do not justify ruling out the possibility of a retinal effect on recognition accuracy. For one thing, the retinal-upright polygons were recognized virtually as accurately as the objective-upright polygons. For another, it was possible that the recognition accuracy for the retinal-control polygons was enhanced, relative to the recognition accuracy for the retinal-upright polygons, as a result of apparent vertical being shifted in a direction opposite to the direction of the subject's head tilt. Regardless of whether

Table 4

Experiment 2: Mean Percent Misses (M) and False Alarms (FA) and Mean d' Scores in the Recognition Test Following Intentional Learning

\begin{tabular}{lccccccc}
\hline & \multicolumn{3}{c}{ Objective } & & \multicolumn{3}{c}{ Retinal } \\
\cline { 2 - 4 } \cline { 5 - 7 } & $\mathrm{M}$ & FA & $\mathrm{d}^{\prime}$ & & M & FA & $\mathrm{d}^{\prime}$ \\
\hline $\mathrm{U}$ & 25.0 & 34.8 & 1.14 & 28.9 & 31.6 & 1.10 \\
$\mathrm{C}$ & 41.8 & 30.9 & .77 & 35.5 & 28.1 & 1.00 \\
$\mathrm{U}-\mathrm{C}$ & & & .37 & & & .10 \\
\hline
\end{tabular}

Note-U = upright: $C=$ control . 
or not retinal orientation influenced recognition performance in this experiment, the critical finding remained that, unlike the results of Experiment 1, evidence for objective spatial reference was obtained.

\section{DISCUSSION}

The results of the two experiments reported in this study supported the hypothesis that an objective spatial reference system would be used only when there was a specific memory requirement involved in the subjects' task. The intentional learning procedure of Experiment 2 fulfilled this requirement, and evidence of objective spatial reference was obtained. This was consistent with previously cited evidence of objective spatial reference when the task required either storing information or retrieving information from long-term memory (e.g., Attneave \& Olson, 1967; Corballis et al., 1976; Rock \& Heimer, 1957). When there was no memory requirement involved in the subjects' task, as was the case for the incidental learning procedure of Experiment 1, there was no evidence of objective spatial reference. Instead, it was found that subjects used a retinal spatial reference system. This was consistent with previously cited evidence of retinal spatial reference in tasks for which there was no memory requirement (e.g., Banks \& Stolarz, 1975; Corballis \& Roldan, 1975; Frost \& Kaminer, 1975; Gillam \& McGrath, 1979; Olson \& Attneave, 1970). Despite the absence of a memory requirement, subjects in Experiment 1 retained retinally referenced representations of visual stimuli. This showed that transformation into an objective reference system is not a necessary condition for perceptual recognition.

The results obtained with the intentional learning procedure (Experiment 2) were consistent with Corballis et al.'s (1976) contention that subjects viewing stimuli from a tilted posture can set their spatial reference system to objective upright prior to stimulus presentation. Support for Rock's (1973) assertion that objective spatial reference is the result of subjects' mentally rotating what are, initially, retinally referenced representations into objective upright would have required that significant effects of both objective and retinal orientation be obtained in the intentional learning condition, which was not the case.

The ability to shift one's spatial reference axes is apparently not universal. For example, Cooper and Shepard (1973) found, in their mental rotation paradigm, that subjects given an orientation cue prior to the presentation of an alphanumeric character were unable to shift their spatial reference axes to conform with the cue. The key to establishing an objective frame of reference, in addition to the use of tasks that include a memory requirement and do not place "excessive" perceptual demands on the subject, may be the availability of proprioceptive orientation information. When subjects with their heads tilted view visual stimuli, vestibular and body-position sensors could provide the orientation information required for them to set their spatial references axes to objective upright.

In conclusion, the results of this study were consistent with the view that different spatial reference systems can be flexibly used to code the orientation of visual stimuli. This coding process seems to involve the assignment of "top" and "bottom" tags to parts of the stimulus, with no specification of the spatial reference system from which these tags are derived (Reisser \& Pick, 1976; Rock, 1957). Although adults are capable of flexibly using different spatial reference systems, Hock and Hilton (1979) have shown that conflicting spatial reference systems can present difficulty, for children, in coding the orientation of visual stimuli. Furthermore, such factors as the shape of a figure (Hock \& Tromley, 1978) and the choice of spatial reference system (Banks \& Stolarz, 1975; Corwin et al., 1977) can influence how broadly subjects "tune" the orientation of a stimulus. The results of the present study add to this literature concerning the coding of orientation information by showing that the inclusion of a memory requirement in the subject's task can have a decisive influence on whether orientation coding will rely on an objective (gravitational) or retinal spatial reference system.

\section{REFERENCES}

Atrneave, F., \& Arnoult, M. The quantitative study of shape and pattern perception. Psychological Bulletin, 1956, 53, 452-471.

ATtne Ave, F., \& Olson, R. K. Discriminability of stimuli varying in physical and retinal orientation. Journal of Experimental Psychology, 1967, 74, 149-157.

ATtNeave, F., \& REid, K. Voluntary control of frame of reference and shape equivalence under head rotation. Journal of Experimental Psychology, 1968, 78, 153-159.

Banks, M. S., \& Stolarz, S. J. The effect of head tilt on meridional differences in acuity: Implications for orientation constancy. Perception \& Psychophysics, 1975, 17, 17-22.

Campbell, F. W., Kulikowski, J. J., \& Levinson, J. The effect of orientation on the visual resolution of gratings. Journal of Physiology, 1970, 207, 635-652.

Cooper, L. A., \& Shepard, R. N. Chronometric studies of the rotation of mental images. In W. G. Chase (Ed.), Visual information processing. New York: Academic Press, 1973.

Corballis, M. C., Anuza, T., \& Blake, L. Tachistoscopic perception under head tilt. Perception \& Psychophysics, 1978, 24, 274-284.

Corballis, M. C., Nagourney, B. A., Shetzer, L. I., \& Stefanatos, G. Mental rotation under head tilt: Factors influencing the location of the subjective reference frame. Perception \& Psychophysics, 1978, 24, 263-273.

Corballis, M. C., \& Roldan, C. E. Detection of symmetry as a function of angular orientation. Journal of Experimental Psy. chology: Human Perception and Performance, 1975, 1, 221-230.

Corballis, M. C., ZBrodoff, J., \& Rolodan, C. E. What's up in mental rotation? Perception \& Psychophysics, 1976, 19, 525-530. 
Corwin, T. R., Moskowitz-Cook, A., \& Green, M. A. The oblique effect in a vernier acuity situation. Perception \& Psychophysics, 1977, 21, 445-449.

De arborn, G. V. N. Recognition under objective reversal. Psy. chological Review, 1899, 6, 395-406.

Frost, B. J., \& Kaminer, J. J. The orientation anistropy and orientation constancy: A visual evoked potential study. Perception, 1975, 4, 51-58.

Gibson, J. J., \& Robinson, D. Orientation in visual perception: The recognition of familiar plane forms in differing orientations. Psychological Monographs, 1935, 46(6, Whole No. 210).

Gillam, B., \& McGrath, D. Orientation relative to the retina determines perceptual organization. Perception \& Psychophysics, $1979,26,177-181$.

Носк, H. S., \& Hilton, T. Spatial coding and oblique discrimination by children. Journal of Experimental Child Psychology, 1979, 27, 96-104.

Hock, H. S., \& Tromley, C. L. Mental rotation and perceptual uprightness. Perception \& Psychophysics, 1978, 24, 529-533.

HoRn, G. The effect of somesthetic and photic stimuli on the activity of units in the striate cortex of unanesthetised, unrestrained cats. Journal of Physiology, 1965, 179, 263-277.

Jung, R., Kornhuber, H. H., \& DAFonseca, J. S. Multisensory convergence on cortical neurons. Progress in Brain Research, $1963,1,207-234$.

Maffe i, L., \& CAmpbell, F. W. Neurophysiological localization of the vertical and horizontal visual coordinates in man. Science, $1970,167,386-387$.

Mille R, E. F. Counterrolling of the human eyes produced by head tilt with respect to gravity. Acta Oto-Laryngologica, 1962, 54, 479-501.

Olson, R. K., \& AtTneave, F. What variables produce similarity grouping? American Journal of Psychology, 1970, 83, 1-21.

Reisser, J. J., \& PICK, H. L. Reference systems and the perception of tactual and haptic orientation. Perception \& Psychophysics, $1976,19,117-121$.

Rock, 1 . The orientation of forms on the retina and in the environment. American Journal of Psychology, 1956, 69, 513-528.
Rock, I. Orientation and form. New York: Academic Press, 1973.

Rock, I., \& Hermer, W. The effect of retinal and phenomenal orientation on the perception of form. American Journal of Psychology, 1957, 70, 493-511.

STE INFELD, $G$. The ef fect of retinal orientation on the recognition of novel and familiar shapes. Journal of General Psychology, 1970, 82, 223-239.

WADE, N. J. Orientation effects on line afterimages. Perception \& Psychophysics, 1972, 12, 409-416.

WADE, N. J. Orientation and spatial frequency effects on linear afterimages: The retinal reference for selectivity-A supplementary report. Perception \& Psychophysics, 1973, 14, 384-386.

\section{NOTES}

1. Of the four subjects composing a pseudosubject, two were male and two were female. A preliminary examination of the data indicated that recognition accuracy was somewhat greater for the females than the males, but the pattern of data across the four test orientations was similar for both sexes. The effect of combining subjects into pseudosubjects was to reduce the frequency with which hit and false alarm rates of 1.0 and 0 were obtained. As a result, the d' scores obtained for pseudosubjects were lower than the artificially inflated $d^{\prime}$ scores that were computed for individual subjects. Nonetheless, the pattern of $d$ 's across the four test orientations and the statistical results were the same regardless of whether the d's were obtained for pseudosubjects or individual subjects.

2. The layout of the data in Tables 3 and 4 suggests that an analysis of the Objective-Retinal by Upright-Control interaction could have been performed. Such an analysis, however, would have been inappropriate, because the two variables were not orthogonal (i.e., the objective-retinal comparison is meaningless for the control orientation).

(Received for publication August 29, 1980; accepted March 16, 1981.) 